\title{
HISTÓRIA EM QUADRINHOS E APARELHOS IDEOLÓGICOS DA CLASSE HEGEMÔNICA: UMA ANÁLISE DA REPRESENTAÇÃO CAMPONESA NA PERSONAGEM CHICO BENTO, DE MAURÍCIO DE SOUSA
}

\section{Comic and ideological apparatus of the hegemonic class: an analysis of the peasant representation in the personage Chico Bento, of Maurício de Sousa}

João Paulo Charrone ${ }^{1}$ Luara da Silva Rocha ${ }^{2}$

\begin{abstract}
RESUMO: O objetivo deste trabalho é contribuir para a leitura social do homem do campo representado pela personagem Chico Bento das História em Quadrinhos (HQs) de Maurício de Sousa. De forma direta, o presente texto procura evidenciar que a figura estereotipada que está sendo transmitida através da personagem Chico Bento afeta a imagem do homem do campo e reforça a desigualdade social, exclusão e preconceito de origem. Mas, por outro lado, essa imagem também pode servir como denúncia à falta de políticas públicas para a população camponesa. Não podemos nos esquecer que esses aspectos são transmitidos e reforçados pela indústria cultural, que é uma ferramenta do mercado capitalista para difundir o conceito de camponês atrasado e preguiçoso. Assim, a presente pesquisa procura apresentar as ideologias disfarçadas dessa representação social, apresentando parte dos motivos que explicam o avanço do estereótipo do homem do campo, bem como, qual foi o objetivo da classe hegemônica nesse processo de avanço tecnológico, industrial e urbano.
\end{abstract}

Palavras-chaves: Chico Bento. Estereótipo. Indústria Cultural. História em Quadrinhos (HQs).

\begin{abstract}
The aim of this work is to contribute to the social reading of the country man represented by the character Chico Bento from Comic Stories (HQs) by Maurício de Sousa. Directly, this text seeks to show that the stereotyped figure that is being transmitted through the character Chico Bento affects the image of the peasant and reinforces social inequality, exclusion and prejudice of origin. But, on the other hand, this image can also serve as a denunciation of the lack of public policies for the peasant population. We must not forget that these aspects are transmitted and reinforced by the cultural industry, which is a tool of the capitalist to spread the concept of backward and lazy peasant. Thus, this research seeks to present the ideologies disguised as this social representation, presenting part of the reasons that explain the advance of the stereotype of the rural man, as well as, what was the objective of the hegemonic class in this process of technological, industrial and urban advance.
\end{abstract}

Keywords: Chico Bento. Stereotype. Cultural Industry. Comic Book (HQs).

\footnotetext{
${ }^{1}$ Doutor em História pela Universidade Federal Fluminense (UFF). Docente no curso de Licenciatura em Educação do Campo (LEdoC), Campus Professora Cinobelina Elvas (CPCE), em Bom Jesus (PI). Membro do Núcleo de Pesquisa e Estudos das Comunidades Camponesas (NUPESCC/UFPI). E-mail: jcharrone@yahoo.com.br

${ }^{2}$ Graduada em Licenciatura em Educação do Campo (LEdoC) pela Universidade Federal do Piauí (UFPI). E-mail: luarasilva1214@hotmail.com
} 


\section{CONSIDERAÇÕES INICIAIS}

O presente artigo tem como objetivo contribuir para a análise da figura social estereotipada do caipira, representado pela imagem da personagem Chico Bento, das Histórias em Quadrinhos (HQs) de Mauricio de Sousa. Nesse sentido, este trabalho tem como ponto de partida fazer uma abordagem ampla da personagem Chico Bento, evidenciando os aspectos negativos e denunciativos da imagem do camponês, representado pela personagem em questão.

Aqui, entendemos que as HQs são produtos da indústria cultural e, portanto, se enquadram na crítica de aparelhamento ideológico do grupo dominante. Nesse sentido, faremos, mais adiante, uma discussão sobre ideologia e indústria cultural. Com isso em mente, tentaremos observar quais são os fatores que contribuem para o processo de criação e de divulgação desse personagem e, de que forma, isso contribuiu para a imagem social do camponês na sociedade brasileira.

Para isso, acreditamos que seja necessário compreender o surgimento das HQs no Brasil e de que forma ela se difundiu. Assim, pretende-se identificar os elementos que contribuam para uma análise do contexto especifico da construção da figura do caipira estereotipado, representado pela personagem Chico Bento; objetiva-se também, identificar quais os modelos de homem do campo que são construídos pelos aparelhos ideológicos da classe dominante e de que forma essa representação de camponês está sendo consumida pela sociedade.

De antemão, vale lembrar que, a grosso modo, os aparelhos ideológicos são ferramentas do Estado e/ou do grupo dominante para oprimir os sujeitos, por meio de qualquer forma de comunicação. Assim, os detentores do poder, para se manter nessa condição, usam, entre outros, das representações estereotipadas para construir uma ideologia e, posteriormente, reforçar essas ideologias.

\section{APORTE TEÓRICO-METODOLÓGICO: INDÚSTRIA CULTURAL E IDEOLOGIA DE MASSAS}

Uma das características da sociedade capitalista é o processo constante de "evolução" industrial. Isso, em termos produtivos, visa aumentar a quantidade e a qualidade de produção nos centros urbanos e expansão econômica-industrial do território. Em termos práticos, assistimos à substituição de mão de obra humana e animal por máquinas e a divisão e a diversificação dos sistemas operacionais de todos os setores produtivos. Tais transformações, resultaram em um processo de globalização que avançou nos centros urbanos, como também, no campo. 
Essa observação, nos faz recorrer a Marx, que nos Grundrisses, fez o seguinte apontamento relativo aos avanços do capital em relação a classe trabalhadora:

Todo o progresso da civilização, ou seja, todo aumento das forças produtivas sociais ou, se quiser, das forças produtivas do próprio trabalho, não enriquece o trabalhador, mas o capitalista, do mesmo modo como os resultados da ciência, das descobertas, da divisão e da combinação do trabalho, da melhoria dos meios de comunicação, da ação do mercado mundial ou do emprego de máquinas. Tudo isto aumenta unicamente a força produtiva do capital, e na medida em que o capital se encontra em oposição com o trabalhador, tudo isto não faz senão aumentar sua dominação material sobre o trabalho. (Marx, s.d. apud GOMEZ, 2004, p. 29)

Portanto, sob a lógica de dominação do capital, qualquer evolução das forças produtivas, não enriquecerá os trabalhadores, ao contrário, se configurará como mais um elemento para consolidar e expandir o poder que o domina, ou seja, o capital.

Para além dos apontamentos de Marx, temos que considerar que esse processo de “evolução" produtiva não se restringe apenas aos diferentes maquinários, ciência e equipamentos tecnológicos, uma vez que há, como bem aponta Walter Benjamin (2012), uma construção ideológica que procura valorizar a ideia de "progresso", como algo difundido e acessível a aqueles que se adequam ao sistema capitalista.

Esses processos afetaram diretamente o modo de vida camponês, que, em meio às transformações, não conseguem desfrutar a contento das "benesses" tecnológicas modernas, restritas, a grosso modo, à elite urbana e rural. Paralelamente a esse contexto, eles ainda são caracterizados como atrasados, sujos, doentes, preguiçosos etc., em contraposição ao modelo de homem/mulher urbano (a), encarada como culto (a), limpo (a), feliz etc.

Desse modo, tais sujeitos são constantemente assediados, moralmente ou fisicamente, para abandonar suas terras e/ou vender sua força de trabalho braçal, já que os postos de maior salário nos latifúndios exigiam maior qualificação, devido às novas tecnologias agrícolas e não agrícolas.

Apesar desse quadro, isto é, do quase nulo acesso às tecnologias, a construção social desvalorizante dos sujeitos do campo e das pressões (políticas, econômicas, jurídicas, estatais, físicas etc.), o camponês continua, dentro de suas contradições, produzindo e resistindo em suas comunidades. Uma das estratégias que eles adotaram, conscientes ou não, para fortalecer o elo e a sua permanência no campo é a valorização de seu modo de vida e de seus costumes.

Assim sendo, este trabalho centrará seu norte, a partir da constatação da resistência dos camponeses, no processo utilizado pelos detentores do capital para esvaziar o campo e se apropriarem das suas propriedades. Especificamente pela divulgação de propagandas e materiais 
diversos em diferentes suportes culturais, com o objetivo de ressaltar, entre outros, a "grande" expansão industrial no Brasil; as "inúmeras" vantagens trazidas pelo desenvolvimento do capitalismo, tais como a geração de mais empregos, saúde de qualidade e todos os demais benefícios possíveis que uma globalização possa oferecer "indiscriminadamente" para qualquer pessoa.

Dito de outro modo, a classe hegemônica, como detentora dos principais meios de comunicação de massa (como rádio, cinema, jornais, televisão, revistas de grande circulação e, de certo modo, as redes sociais), busca difundir seus próprios interesses, não se importando com a exclusão e conteúdo social que eles difundem, procurando, assim, controlar e organizar a sociedade. Nas palavras de Adorno (2002, p. 07):

Distinções enfáticas, como entre filmes de classe A e B, ou entre histórias em revistas e diferentes preços, não são tão fundadas na realidade, quanto, antes, servem para classificar e organizar os consumidores a fim de padronizá-los. Para toda alguma coisa é prevista, a fim de que nenhum possa escapar; as diferenças vêm cunhadas e difundidas artificialmente. $O$ fato de oferecer ao público uma hierarquia de qualidades em série serve somente à quantificação mais completa, cada um deve se comportar, por assim dizer, espontaneamente, segundo o seu nível, determinado a priori por índices estatísticos, e dirigir-se à categoria de produtos de massa que foi preparada para o seu tipo.

De acordo com Adorno (2002), cada meio de comunicação de massa, seja ele qual for, produz aquilo que é mais necessário para atender todos os níveis do "mercado", dessa forma, a classe hegemônica consegue, com maior eficiência, difundir sua ideologia para diferentes públicos da sociedade. Assim sendo, esse grupo "produz" materiais de propaganda específicos para cada público alvo. Ou seja, a classe hegemônica procura alienar os diferentes sujeitos sociais, a partir de uma tentativa de controle das ferramentas de dominação cultural. Cabe lembrar que essa dominação não é totalizante, afinal temos que considerar no mínimo duas situações: 1) não se pode garantir que o consumo desses produtos sejam inteiramente passivos por parte da sociedade; 2) existem, no campo cultural, perspectivas e produtos contrários à ordem hegemônica. Infelizmente, por questão de tempo, não teremos condições nesse trabalho de analisar essas duas condições.

Dito isso, não podemos nos esquecer que:

A arte e a cultura estão, neste século, inseridas no universo econômico, como atividade de exploração e expansão do capital, e participam também do universo simbólico como um dos mecanismos privilegiados de sedimentação do imaginário dominante. Os meios preferenciais de exercício da hegemonia são os veículos de difusão da informação e da cultura de massas. (BOLOGNESI, 1996, p. 83) 
De acordo com a citação, as formas artísticas estão vinculadas as transformações sociais e aos meios de "expansão industrial", assim, elas podem tanto corroborar ou fazer crítica a esse processo. No entanto, as mídias de massa e de grande circulação, como aparelhos ideológicos de dominação dos grupos hegemônicos, servem para consolidar a dominação simbólica e alienante dos sujeitos sociais, escamoteando as diferentes dominações do mercado capitalista. Todas as formas de reprodução contribuem para a propagação das diferentes mercadorias da classe hegemônica, que, ao serem produzidas, se tornam um objeto de alienação social em uma sociedade fragmentada pela expansão do capital ou da indústria. Nas palavras de Adorno (1997) apud Fianco (2010, p. 134):

\footnotetext{
Assim, através de um mecanismo psicológico que prefere uma mentira bem arquitetada a uma verdade contundente, a indústria cultural forma as verdades convenientes através dos meios de comunicação em massa e propaga a ideologia e o conjunto de valores que mais lhe interessa. A verdade, então transformada em um exercício de poder, serve com sua inverdade à dominação social mediante a propagação da ideologia, que é tão opressiva quanto os antigos sistemas despóticos e transforma em trabalho de Sísifo qualquer tentativa de uma verdade que se oponha a isso, pois ela porta consigo tanto o 'caráter do inverossímil como é, além disso, pobre demais para entrar em concorrência com o aparato de divulgação altamente concentrado.
}

O processo de expansão industrial ocasionou a difusão das mercadorias em diferentes escalas do mercado, sendo seu principal foco, o lucro imediato e satisfação econômica. Para tal, a classe hegemônica procura, por meio do controle das produções midiáticas de grande circulação, construir uma narrativa mentirosa e reversa sobre a sociedade de consumo capitalista. Nesse sentido, tal aparato ideológico, a serviço dos poderosos, idealiza tornar seus consumidores (telespectadores, leitores, ouvintes etc.) em meros fantoches em suas mãos. Lembramos, mais uma vez, que tal "dominação" não se efetiva em sua totalidade.

Tal processo se fundamenta grosseiramente em duas estratégias: 1) difundir uma imagem exclusivamente positiva dos "avanços" e do capitalismo per se. Por extensão, qualquer "viés, realidade ou visão paralela" é automaticamente condenada; 2) vender uma narrativa que procura fazer a sociedade acreditar que tudo que se passa nos meios de comunicação de grande massa são puramente verdadeiros.

Essa conclusão parcial nos leva a fazer breves considerações sobre outro conceito: a ideologia. Afinal, ela ajuda a nos explicar, entre outras coisas, o desejo de pertencer a um determinado grupo e o de consumir uma mercadoria, muitas vezes, apenas por ter sido idealizado por um sistema midiático ou uma figura pública. Como nos lembra Ortiz (2006, p. 99): “Seria uma 
ilusão imaginarmos uma sociedade sem ideologia, pois é por meio dela que os homens tomam consciência de si mesmos, dos outros, e atuam no mundo".

A reflexão gramsciana sobre ideologia aponta que a classe social subordinada, mesmo possuidora de uma leitura de mundo embrionária e desunida, toma emprestada de outra classe social, devido a seu estado de submissão e subordinação intelectual, uma concepção ideológica que lhe é excêntrica, abraçando-a não tanto porque nela acredita, mas devido a seu comportamento não ser independente e autônomo (SIMIONATTTO, 2004).

E aqui, cabe destacar o papel dos "intelectuais tradicionais" e dos aparelhos de dominação, que, contrariamente ao intelectual orgânico de Gramsci (2007), trabalham para difundir uma visão de mundo que pertence as elites, propagando "verdades universais", mas que, na verdade, são "verdades" de uma determinada classe.

Dito isso, trazemos para esse debate, Adorno (1982, p. 261). Segundo esse autor:

No entanto, o conteúdo de verdade pode afirmar-se mesmo nas obras de arte muito profundamente ligadas à ideologia. Enquanto aparência socialmente necessária, a ideologia constitui também sempre em tal necessidade a forma discordante do verdadeiro.

A ideologia, em Adorno (1982), como podemos ver está atrelada à falsa consciência, isto é, um obstáculo à tomada de consciência por parte da classe dos trabalhadores. Portanto, segundo o autor, ela busca esconder a "realidade concreta". Ou seja, por trás dos fatos reais a classe hegemônica sempre tentará construir certas narrativas que terão conteúdo "não verdadeiro". Entre os elementos que ajudam esse grupo a tentar manter sob controle a ideologia hegemônica no sistema capitalista podemos incluir os gêneros textuais. Compreendermos através de Adorno e da Escola de Frankfurt, as diferentes concepções sobre cultura de massas e ideologia e como elas manipulam a sociedade. Desse modo, é possível perceber, segundo Fianco (2010, p. 128) que: “[...] os reflexos da dominação e da opressão dos seres humanos pelas estruturas da sociedade em que vive através da ideologia que, propagada pelas campanhas publicitárias e pelos bens culturais de consumo massivo".

Todas as formas de manipulação, via indústria cultural, são voltadas para a massificação ideológica. Para isso, ela tenta se expandir difundindo diversos ideários sociais, para diferentes grupos sociais, em troca de grandes lucros (não apenas econômico, mas também, simbólico). Afinal, como sabemos, os capitalistas possuem como fim último, o acúmulo de capital, para isso, buscam, entre suas estratégias, a dominação social por meio da massificação de narrativas.

Nesse sentido, a ideologia por trás das grandes produções midiáticas e através dos bens culturais procuram tornar as pessoas menos reflexivas e, concomitantemente, que consumam para 
além do que precisam e, se possível, acima dos níveis do está sendo produzido. Via de regra, temos que lembrar que existem ao menos dois tipos de produções midiáticas à serviço do capital: 1) aquelas que são explicitamente "propagandas" de consumo, como aquelas que são anunciadas nos intervalos comerciais das rádios e das televisões; 2) aquelas que são implicitamente difusoras de veículos de propaganda e de concepções de mundo, elas citamos as HQs. Afinal, esse gênero se enquadra como produções artísticas massificadas e massificadoras, ou seja, são produtos do universo simbólico capitalista.

Uma das temáticas ao qual Adorno dá ênfase em seus escritos é a questão da subjetividade. Além de fazer uma análise sobre a cultura e como os processos industriais dominam os seres humanos, tornando-os mais vulneráveis às produções culturais de massas existentes na sociedade, pois em uma sociedade em que existem avanços tecnológicos até as pessoas se tornam mercadoria. Uma vez que, além de fornecer mão de obra barata, consomem mais do que ganham e assim, o mercado capitalista se propaga, tornando os seres reprodutores, consumidores e alienados ao sistema, que só cresce por meio de grandes publicidades e produções midiáticas. Bem como, usando diversas alternativas, coercitivas ou não, aprisiona as pessoas as regras do jogo capitalista.

$\mathrm{Na}$ sociedade de comunicação em massa e de pleno consumo, a propagação de valores morais manipulados se dá nos mais diversos âmbitos da vida cotidiana e a necessidade de sobrevivência suplanta completamente a possibilidade de resistência de uma subjetividade enfraquecida. E um dos maiores perigos ocasionados por tal esvaziamento do sujeito, por sua incapacidade de análise crítica, está no potencial político que a penetração estética e propagandística da cultura aceita sem reservas não apenas provocar como realmente, para tristeza e vergonha da humanidade. (FIANCO, 2010, p. 134)

De tal modo, a reprodução cultural de massas só reproduz de fato o que lhe convém e não se importa com veracidade das suas reproduções e, muito menos, com a emancipação de seu público. Ao contrário, elas procuram favorecer seus bens de consumos e não a sociedade como um todo. Por trás da indústria cultural, existe um sistema financeiro que busca oprimir o sujeito de forma subjetiva. Por meio da ideologia, o capitalismo consegue atingir o psicológico humano tornando as pessoas mais vulneráveis para a propagação e o consumo dos bens de consumo. Devemos salientar que, durante o processo de industrialização todas formas de cultura viraram bens de consumo, incluindo aqui, por extensão as HQs.

Devemos ressaltar também, que a classe hegemônica faz de tudo para desqualificar os povos do campo, afinal, faz parte de suas aspirações, a expansão capitalista fundiária. E, aqui, recorremos a Marx (1998, p. 570-571), quando afirma que: 
$\mathrm{Na}$ agricultura moderna, como na indústria urbana, o aumento da força produtiva e a maior mobilização do trabalho obtêm-se com a devastação e a ruína física da força de trabalho. E todo o progresso da agricultura capitalista significa progresso na arte de despojar não só o trabalhador, mas também o solo; e todo aumento da fertilidade da terra num tempo dado significa esgotamento mais rápido das fontes duradouras dessa fertilidade. Quanto mais se apoia na indústria moderna o desenvolvimento de um país, como é o caso dos Estados Unidos, mais rápido é esse processo de destruição. A produção capitalista, portanto, só desenvolve a técnica e a combinação do processo social de produção, exaurindo as fontes originais de toda a riqueza: a terra e o trabalhador.

Entre as estratégias utilizadas por esse grupo é propagar diferentes ideários, seja para manipular o camponês, fazendo que eles abandonem suas terras; seja construindo uma imagem negativa dessa classe diante da sociedade como um todo, como a representação de atrasados e/ou obstáculos do avanço tecnológico.

Realizados esses breves apontamentos teóricos-metodológicos, passamos ao próximo tópico, ao qual pretendemos explorar a imagem estereotipada de Chico Bento nas HQs.

\section{CHICO BENTO E A PERSONIFICAÇÃO ESTEREOTIPADA DO CAMPESINATO BRASILEIRO}

\subsection{Contextualização das Histórias em Quadrinhos (HQs) no Brasil}

O objetivo aqui é fazer um rápido panorama, sem aprofundamento contextual, por questão de tempo e escopo do artigo, mas que julgamos necessário, para entendermos um pouco melhor nosso objeto. Afinal, como afirmou Anselmo (1975) apud Gomes (2008, p. 03): "Não existe no Brasil uma linha autenticamente nacional de desenvolvimento de HQ, sendo a importação responsável pela introdução das HQ neste país”.

A História em Quadrinhos teve início no Brasil nos anos de 1867, pelo autor Ângelo Agostini. Suas produções eram mais destinadas para os adultos, pois os conteúdos eram majoritariamente voltados para os aspectos sociais e políticos da época. O supracitado autor lançou através da revista "Vida Fluminense", no ano de 1869, a primeira história em quadrinhos que se chamava "As Aventuras de Nhô Quin”. Essas histórias retratavam em seus episódios as adversidades de um cidadão simples do interior do Brasil (NATAL, 2005).

No entanto, ainda que pese que havia chegado no país aparelhos gráficos tecnológicos, na passagem do século XIX e no começo do século XX, as revistas eram mais populares apenas nos países mais desenvolvidos, nesse sentido, muitos autores que se destacaram nos primeiros anos nas HQ eram estrangeiros. 
Desse modo, foi com Adolfo Aizen, pela revista "Suplemento Infantil", em 1934, que os brasileiros tiveram uma experiência com os personagens em quadrinhos dedicada às imagens de super-herói e diversos personagens de figuras públicas americanas. Desse modo, de acordo com Gomes (2008, p. 04), “com a publicação do Suplemento Juvenil é possível observar também o início da formação de um incipiente mercado editorial brasileiro, com o surgimento de jornalistas e empresários que são atualmente nomes de força dentro da imprensa do Brasil”. (Grifo do autor)

Vale lembrar que as HQs passaram, ao longo do século XX, no mundo todo, por muitas críticas. Citamos, por exemplo, o fascismo que proibiu sua circulação. Não foi diferente no Brasil:

No Brasil, o ataque às $H Q$ s pegou carona com os grupos conservadores, mas também contava com outros objetivos: a disputa por espaço dentro da imprensa brasileira, em especial por aquela fatia ocupada por Roberto Marinho. Esta dinâmica de concorrência, que em muitos momentos beirou o sensacionalismo, caracterizou a produção brasileira de quadrinhos. (JÚNIOR, 2004 apud GOMES, 2008, p. 05)

Em sentido oposto, também houve manifestações expressivas a favor das HQs. Elas, a médio e longo prazo, convenceram a sociedade de que esse gênero textual contribui para a sociedade de forma positiva. Entre esses elementos, podemos citar a construção social do sujeito e sua utilização como uma ferramenta com fins educativos.

Aproveitando desse ambiente pró-HQs, que Adolfo Aizen começou a publicar as suas revistas mais populares, como Superman, o Batman e Zorro. Com algumas adaptações, essas obras foram publicadas em forma de HQs, batizadas com o título de "Edições Maravilhosas".

As Ediçoes Maravilhosas se limitaram durante um bom tempo a colocar no mercado
material estrangeiro - alguns inclusive já publicados anteriormente por Aizen em
outras oportunidades -, passando em um segundo momento à literatura nacional:
Dinah Silveira de Queiroz e Cecília Meireles serão alguns nomes que tiveram
obras quadrinizadas pelas Edições Maravilhosas. A EBAL publica também
biografias de nomes importantes da história nacional e descobertas científicas
sob o formato das HQ. (JÚNIOR, 2004 apud GOMES, 2008, p. 07) (Grifos do
autor)

No que tange as primeiras experiências desse gênero textual, destinado ao público infantil, no Brasil, destacamos entre as revistas de vanguarda a: "O Tico-Tico", que, segundo Gomes (2008, p. 05): "inseriu-se durante boa parte de sua trajetória em um mercado já amplamente dominado pelos comics norte-americanos desde os anos 1930 e 1940".

Portando, as HQs só tomam forma de massa no país em grande medida por influência dos EUA. Evidentemente, que tal importação não se limitou unicamente à esfera da edição, formatação das revistas e entretenimento. Para além disso, esses textos se transformaram em mais 
uma ferramenta a serviço da construção de valores e ideologias do capitalismo, bem como, ao papel de preponderância dos EUA no Brasil. Nas palavras de Tota (2000) apud Gomes (2008, p. 06):

\begin{abstract}
A relação entre os quadrinhos e as referências culturais do Brasil são claras aqui. Dos quadrinhos lançados pela revista à moda francesa $O$ Tico-Tico, vamos à publicação em massa de comics norte-americanos; do ideal de afrancesamento, característico da sociedade do Rio de Janeiro de início do século passado - vide a importação de pardais objetivando tornar a cidade mais parecida com Paris (SEVCENKO, 2004) -, observamos gradativamente o alinhamento do país à cultura de massas norte-americana, com seus gostos e padrões - o que por sua vez relaciona-se também a um contexto de boa-vizinhança entre os dois países. (Grifos do autor)
\end{abstract}

Ou seja, percebe-se nas publicações voltadas para o público brasileiro, quase sempre, uma ligação com os norte-americanos. Influência ideológica e comportamental que é sentida claramente nos dias de hoje.

Para além disso, durante um tempo as HQs passaram por várias acusações. Sendo considerada 'subliteratura' ou material subversivo. Essas forçaram as HQs a passassem por várias modificações e adaptações para serem novamente comercializadas em todo o país. Nesse contexto de perseguições, algumas dessas HQs ficaram sem circular durantes anos.

As HQs só se tornaram efetivamente populares na esfera nacional durante a década de 1930. Nesse período, estávamos vivendo no plano econômico, o início do processo de industrialização. Essa nova conjuntura afetou o campo cultural, e, com isso, surgiram diversos sistemas que facilitaram a exposição das diferentes artes do mundo. Nesse processo, vários atores se destacaram. Entre eles, está Mauricio de Sousa, figura essencial para a construção do desenvolvimento da difusão das HQs no Brasil.

Ele, desde muito cedo, publica suas tirinhas em forma de quadrinhos. Mas, no que tange à origem das personagens que orbitam a Turma da Mônica devemos retornar ao ano de 1959. Nesse ano, Mauricio de Sousa lança pelo jornal "Folha da Manhă” a produção “As Aventuras de Bidu”. Bidu era um cachorro de cor azul, cujo dono era o Franjinha. Dalí em diante, surgiram paulatinamente as demais personagens. Vale destacar que, em 1970, o autor de Chico Bento lançou suas HQs na forma de revista, tornando assim, mais populares suas narrativas literárias.

\title{
3.2 A imagem e o modo de vida da personagem Chico Bento
}

Chico Bento, personagem fictício que representa um camponês, foi criado no ano de 1961, mas só foi lançado em 1963, pelo autor Mauricio de Sousa (NATAL, 2005). A personagem só foi lançada como revista em 1982. Esse autor retrata-o imageticamente, de acordo com o estereótipo 
vinculado pela indústria cultural do homem do campo. Ou seja, é a personagem da Turma da Mônica que usa chapéu de palha, uma bermuda xadrez remendada, um cordão para segurar o calção, que possui uma pequena imperfeição nos dentes da frente, que não usa de forma mais acentuada os calçados, que possui um sotaque diferente dos demais personagens, e é, às vezes, preguiçoso.

Figura 1: Exemplo da imagem de Chico Bento

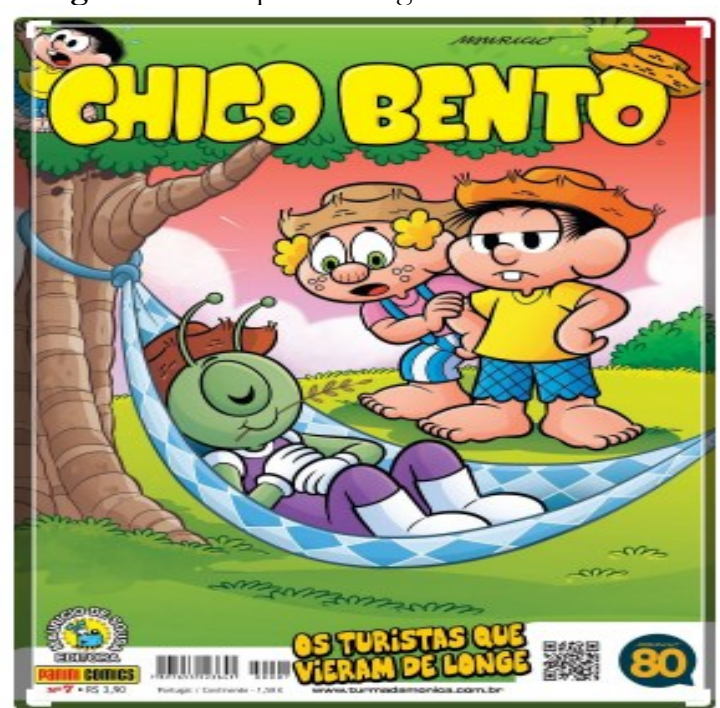

Fonte: $<$ https:/ br.pinterest.com/pin/604678687444420539/visual-search/?cropSource $=6 \& \mathrm{~h}=780 \& \mathrm{w}=538 \&$ $\underline{x=16 \& y=10}>$. Acesso em: 23 abr. 2020.

Segundo seu criador, a personagem é uma representação do seu tio-avô, ou seja, a personagem foi inspirada no tio-avô e na avó de Mauricio de Sousa. A primeira versão dessa personagem, era voltada para o público adulto, portanto, teve que passar por várias transformações até os dias atuais. Modificações essas, que abrangem desde a variação linguística até o público alvo.

Mauricio de Sousa lançou a primeira revista da personagem Chico Bento em 1982. Com diferentes personagens, Chico Bento se dava bem com todos os outros personagens, mas ele era representado como um camponês atrasado, excluído das novas tecnologias. Diferentemente das demais criações desse autor, ele era filho único e morava em um sítio, em uma casa humilde com seus pais. Sua família era bem simples, mostrando o camponês de forma estereotipada, sua família criava diversos animais, bem como, cultivavam seus próprios alimentos.

Chico Bento gostava de ouvir as histórias que sua "Vó Dita" contava. Além disso, tinha um cuidado especial com todos os animais do sítio. Vale lembrar, que ele possui um "par" romântico, a personagem Rosinha. Nas narrativas de Chico Bento, percebemos seus principais hábitos: gosta de tirar uns cochilos; tem como bobby preferido: nadar no ribeirão pelado e pegar goiabas escondidas do seu vizinho. Para além disso, Chico Bento é um garoto que fala um “português do campo". Tal característica, o sotaque camponês, é marcadamente explorado pela indústria cultural como algo negativo e considerado como algo fora do padrão correto. Certamente, 
reforçando o preconceito e a imagem de atrasado, bronco e inculto do camponês, também contribuindo para caracterizar o linguajar do camponês em diferentes espaços.

Não podemos esquecer que a imagem da personagem Chico Bento, às vezes, é comparada a personagem Jeca Tatu, de Monteiro Lobato.

Figura 2: Imagem do Jeca Tatu retratado por Belmonte, na revista Vamos Ler (1946, p. 06)

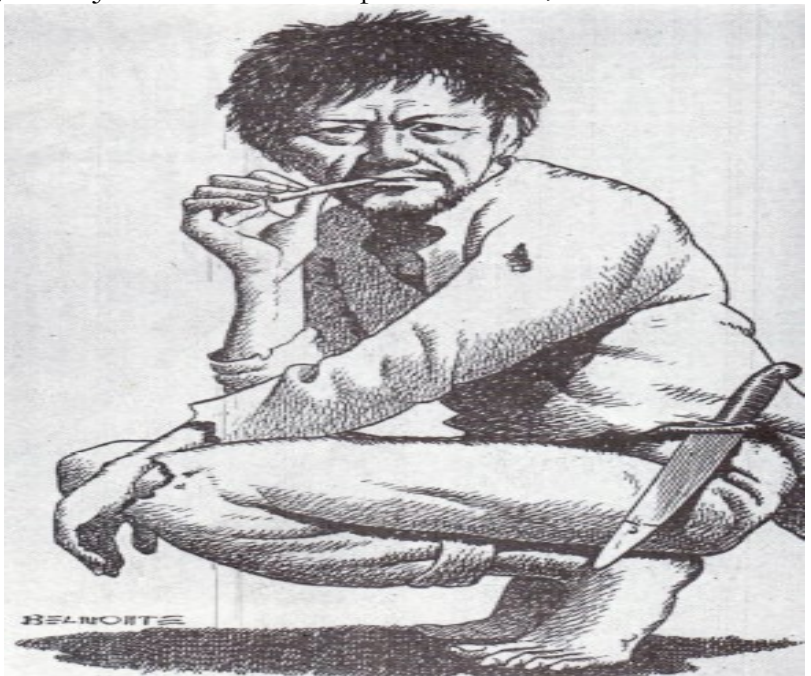

Fonte: Acervo da Biblioteca Nacional apud Lima (1999, p. 198)

Esse último personagem é marcado como um camponês sem qualquer tipo de qualidade, que em muitos dos episódios é sempre preguiçoso, desleixado e que vive sem as mínimas condições básicas de saúde. Ou seja, trata-se do estereótipo do camponês sem políticas públicas.

Ao observar o caipira Chico Bento em sua essência, é possível encontrar características do caboclo Jeca Tatu. Essa personagem, evidenciada no livro Urupês de Monteiro Lobato (1882 -1948), representa um caboclo pobre, que residia em uma casinha de sapé localizada na mata. Sobrevivia na pobreza, juntamente com sua mulher e seus filhos, descritos como magros e desnutridos. Ele passava os dias de cócoras, desanimado, e sempre pitando cigarros de palha. No mato, caçava, pescava, retirava palmitos, mandioca, contudo, não tinha ideia de plantar nada próximo de sua casa. Várias são as aproximações entre essas duas visões do homem interiorano nacional, sejam intencionais ou não. Ambos são preguiçosos, tranquilos, não usam calçados, nascem e vivem no meio rural e representam o homem da roça, salvo, de maneira estereotipada. (BENTO, 2009, p. 6482).

O estereótipo criado através desses personagens nos mostra que os autores representam um camponês quase como uma "coisa", com o linguajar diferenciado, com outro padrão físico quando comparado ao "urbano".

Ao pensar nos estereótipos relacionados à figura do homem do campo existentes na memória coletiva da sociedade brasileira, é possível eleger personagens que 
colaboraram e, ainda colaboram, para povoar o imaginário nacional acerca do que é ser "caipira". Na literatura, encontra-se a figura do Jeca Tatu, criação de Monteiro Lobato. No cinema fotográfico, há o Jeca criado por Mazzaropi. Nos quadrinhos e nos desenhos animados, a personagem Chico Bento. (BENTO, 2009, p. 6482)

Maurício de Sousa também comunga dessa mesma caracterização, como temos visto, na personagem de Chico Bento. Ou seja, percebe-se que até os dias atuais, Chico Bento apresenta as mesmas características da representação do camponês do século passado. Desse modo, podemos concluir que a narrativa construída pela indústria cultural sobre o campesinato brasileiro não sofreu mudanças:

Percebe-se, certamente, que Chico Bento continua protagonizando histórias, no entanto, após as mudanças estéticas ocorridas até 1982, já se passaram 26 anos e o "caipirinha" de Maurício de Sousa não se contemporaneizou. Ora, ele ainda possui hábitos e costumes característicos do período de sua criação e continua distante dos meios tecnológicos. (BENTO, 2009, p. 6482)

Como podemos observar, a personagem Chico Bento transmite atraso em relação aos novos meios de tecnologia. Ele é rustico em relação ao homem da cidade. Segundo Maurício de Sousa, por ser uma figura representativa do homem do campo para o público infantil, Chico Bento não se questiona tanto sobre suas vestimentas, seu linguajar, seu modo de vida e sua característica física (NATAL, 2005). Vale ressaltar, mais uma vez, que esse estereótipo predominante na atualidade se deve a massificação cultural, iniciada no período de industrialização no Brasil.

Feita essa rápida caracterização da personagem, percebemos que um dos elementos levantados nas histórias de Chico Bento é o preconceito e o estereótipo que foram propositalmente difundidos sobre o campesinato brasileiro. Dito de outro modo, a partir da representação de Chico Bento como o "típico" camponês, podemos ver a caricatura do homem do campo, que vive supostamente seu cotidiano de forma inocente, por estar ligado a seus valores, costume, culturas e suas raízes. Em suma, uma personagem que transmite um estilo de vida atrasado pela extrema simplicidade/pobreza e que tem seus próprios princípios e que ama a natureza em oposição ao ambiente urbano: tecnológico, limpo, belo, agitado, progressista etc.

Por outro lado, o campo é apresentado como um espaço de pasmaria, já que consiste em um local onde o atraso é uma constante e, sob minha ótica, em que os habitantes são um tanto retrógrados e desprovidos de informações. Assim sendo, "a metrópole apresenta-se como espaço dicotômico em relação ao campo, [...] emergem como oposição à tranquilidade e sossego do 'interior"'. (PARRILLA, 2006 apud BENTO, 2009, p. 6485) 
Vale lembrar que, o período de gênese do Chico Bento, o Brasil passava por um processo de transformação. No plano econômico, o país tinha recém se industrializado; no plano cultural, diferentes setores artísticos começaram a ser consolidar. Esse último setor, conforme aponta Benjamin (2012), especificamente os voltados a massificação ideológica, como vimos mais acima, tornou-se mundialmente uma forma de mostrar e valorizar os novos avanços tecnológicos em todos os meios visíveis de comunicação e de públicos.

Assim, as HQs, entre outas revistas, estiveram a serviço do capitalismo para retratar certos aspectos e valorizar certos costumes e consumo da sociedade brasileira. Como também já dissemos, nesse boom tecnológico muitas coisas não foram reproduzidas com forma de mostrar a realidade concreta, mas sim, de construir uma narrativa ideológica que favoreça os grupos hegemônicos. Conforme apontam Horkheimer; Adorno (1973, p. 200):

Essa adaptação realiza-se mediante os produtos da indústria cultural; como o cinema, as revistas, os jornais ilustrados, rádio, televisão, literatura de best-seller dos mais variados tipos, dentro do qual desempenham um papel especial as biografias romanceadas.

Desse modo, uma parte significativa das representações que surgiram com a expansão da industrial no Brasil são produtos dessa indústria cultural. A classe hegemônica, para se manter como tal, procura abordar e difundir seus valores em diferentes correntes, com o intuito de transformar ou de configurar o imaginário social.

\section{CONSIDERAÇOES FINAIS}

De acordo com a figura do camponês retratada na personagem de Chico Bento, podemos considerar que é uma personagem estereotipada. Afinal, ela relata um camponês atrasado, preguiçoso, que fala um linguajar diferenciado, com roupas padronizadas, sempre anda descalço e que usa chapéu de palha. Nesse sentido, um questionamento cabível seria: de fato, existe, ou já existiu, um camponês com essa característica? Mas, essa não foi a pergunta norteadora dessa pesquisa, pois, a comprovação, ou não, dessa imagem, por si só, é pouco significativa. Abaixo explicitaremos os motivos do porquê consideramos tal questão como pouco relevante.

Em primeiro lugar, há, temporalmente e geograficamente, no Brasil diferentes concepções de camponês. Portanto, não se pode fazer uma generalização do camponês, como se faz na personagem de Chico Bento, de Mauricio de Sousa, Jeca Tatu de Monteiro Lobato, Jeca Tatu de Mazzaropi etc. 
Em segundo lugar, porque qualquer oposição de cultura, como a urbana versus a camponesa, com o intuito de construir uma classificação hierárquica é um erro, pois, tanto a cultura urbana, como a cultura camponesa, apesar de possuírem muitos elementos distintos, possuem a sua importância particular na constituição e na atual formação da sociedade brasileira. Em outras palavras, cultura é sempre cultura.

Em terceiro lugar, esse estereótipo é fruto da cultura de massa, produto da indústria cultural, logo, vinculada ao capitalismo, que vê na cultura camponesa um obstáculo ao seu pleno desenvolvimento. Afinal, o modo de produção camponês é voltado, em primeiro lugar, para subsistência, além disso, ele cria diversos animais de forma muito diferente do sistema econômico hegemônico, por exemplo, os nomeando, bem como, tratando-os como de estimação. Vale ressaltar que essas características são acentuadas nas histórias de Chico Bento.

Em quarto lugar, podemos usar do estereótipo criado nessas representações para fazer uma denúncia em favor daqueles que vivem no campo. Em outros termos, a partir dessa visão de atraso, podemos refletir sobre questões essenciais para uma vida de qualidade para o camponês, tais como: acesso a terra, saneamento básico, água canalizada, saúde e educação de excelência, bem como, suporte técnico, eletricidade etc. Isto é, cobrar uma Reforma Agrária concreta e plena. Ou seja, podemos usar essas representações parcialmente consolidadas na sociedade para construir uma narrativa contra hegemônica, enfatizando, por exemplo, a negligencia do setor público.

Nesse sentido, propomos que, a partir desses fatores negativos existentes no discurso capitalista sobre o campo, passemos a olhar a realidade como ela é não como está sendo idealizada, para que, desse modo, possamos ter uma visão mais ampla do que o camponês concretamente precisa. Para isso, certamente precisaremos dar mais visibilidade e voz a essa classe social, que tanto necessita de políticas públicas, como também, necessitaremos de energias que mudem o cenário produtivo, educativo, infraestrutural, ideológico etc., descontruindo essa representação estereotipada e repassada de gerações em gerações até os dias de hoje sobre o camponês, como matuto, atrasado, que não sabe das coisas, que vive uma vida monótona e sem perspectivas.

Em quinto lugar, também devemos considerar que o campesinato atual, considerando sua multiplicidade de costumes, hábitos, modos de vida etc., distanciou-se dos perfis apresentados no século passado (Jecas Tatus e Chico Bento). Ou seja, o camponês está inserido - com todas as dificuldades e contradições - no mundo capitalista globalizado. Assim sendo, parte dos homens e das mulheres que vivem no campo, mesmo mantendo parte de suas tradições e modos de vida, são influenciados pelas tecnologias e práticas inovadoras, tanto no modo de produção, como no seu modo de viver. 
Em síntese, esse artigo se propôs, considerando a diversidade e complexidade do universo camponês brasileiro, colocar-se como uma narrativa que procura desconstruir o discurso hegemônico sobre o perfil de camponês na personagem Chico Bento e por outras representações culturais de massa, afinal, elas retratam de forma muito parcial sobre o concreto/real do universo camponês.

Temos que ter ciência que estamos diante de um desafio imenso, pois se trata de reverter o estereótipo e uma narrativa construída pela indústria cultural secular. Mas, apesar de exigir um trabalho hercúleo, acreditamos que seja possível mudar essa concepção de campo e camponês como algo ligado a atraso e fora de nosso tempo. Para isso, será necessário novas pesquisas e movimentos culturais que, de fato, abordem a realidade do camponês, de forma não estereotipada. Tais ações e trabalhos demandam também, uma ampla divulgação, daí a necessidade de uma grande articulação entre os sujeitos, os movimentos e a mídia contra-hegemônica.

\section{REFERÊNCIAS}

ADORNO, Theodor W. Teoria da cultura de massa. Rio de Janeiro: Paz e Terra, 1982.

ADORNO, Theodor W. Indústria Cultural e Sociedade. São Paulo: Paz e Terra, 2002.

BENJAMIN, Walter. Magia e técnica, arte e política: ensaios sobre literatura e história da cultura. São Paulo: Brasiliense, 2012.

BENTO, Franciele. Chico Bento: a representação do caipira nos desenhos animados. In: IX Congresso Nacional de Educação (EDUCERE) e III Encontro Sul Brasileiro de Psicopedagogia. Anais eletrônicos... Paraná: PUC-PR, out. 2009. p. 6477-6491. Disponível em: < https://educere.bruc.com.br/arquivo/pdf2009/2804 1264.pdf >. Acesso em: 22 out. 2019.

BOLOGNESI, M. F. The cultural commodity. Trans./Form./Agano, São Paulo, v. 19, p. 7586, 1996.

FIANCO, Francisco. Adorno: Ideologia, cultura de massa e crise da subjetividade. Revista Estudos Filosóficos, São João del-Rei/MG, n. 4, p. 128-142, 2010. Disponível em: < http://www.seer.ufsj.edu.br/index.php/estudosfilosoficos/article/view/2356/1629 >. Acesso em: 22 out. 2019.

GOMEZ, André Villar. A dialética da natureza de Marx: os antagonismos entre capital e natureza. 2004. 103 f. Dissertação (Mestrado em Filosofia) - Centro de Teologia e Ciências Humanas. Pontifícia Universidade Católica do Rio De Janeiro (PUC-Rio), Rio de Janeiro, 2004. Disponível em: < https://www.maxwell.vrac.puc-rio.br/4924/4924 1.PDF $>$. < https://www.maxwell.vrac.puc-rio.br/4924/4924 6.PDF >. Acesso em: 28 fev. 2020.

GOMES, Ivan Lima. Uma breve introdução à história das Histórias em Quadrinhos no Brasil. In: VI Congresso Nacional de História da Mídia. Anais eletrônicos... Rio de Janeiro, 2008. p. 01-15. Disponível em: < http://www.ufrgs.br/alcar/encontros-nacionais-1/encontros-nacionais/6o- 
encontro-2008- $1 / \mathrm{Uma} \% 20$ breve $\% 20$ introducao $\% 20 \mathrm{a} \% 20$ historia $\% 20$

das $\% 20$ historias $\% 20 \mathrm{em} \% 20$ quadrinhos $\% 20$ no $\% 20$ Brasil.pdf $>$. Acesso em: 05 mai. 2020.

GRAMSCI, Antonio. Quaderni del Carcere: edizione crittica dell'Istituto Gramsci a cura di Valentino Gerratana. Torino: Einaudi, 2007, vol. 4.

HORKHEIMER, M.; ADORNO, T. W. Temas básicos da Sociologia. São Paulo: Cultrix, 1973.

LIMA, Nísia Trindade. Um sertão chamado Brasil: intelectuais e representação geográfica da identidade nacional. Rio de Janeiro: Revan: IUPERJ, UCAM, 1999.

MARX, Karl. O capital. Livro I. Rio de Janeiro: Civilização Brasileira, 1998.

NATAL, Chris Benjamim. Os universos de Chico Bento - estereótipos, elementos de funcionamento universal e produção de sentido nestes quadrinhos de Maurício de Souza. In: XXVIII Congresso Brasileiro de Ciências da Comunicação, Anais eletrônicos... Rio de Janeiro, set. 2005. p. 01-15. Disponível em: <

http://www.intercom.org.br/papers/nacionais/2005/resumos/R0160-1.pdf > . Acesso em: 11 nov. 2019.

ORTIZ, Renato. Notas sobre Gramsci e as Ciências Sociais. Revista Brasileira de Ciências Sociais, vol. 21, n. 62, pp. 95-103, out., 2006.

PersonagenS - Turma do Chico Bento. In: Portal Turma da Mônica. São Paulo, 1996-2. Disponível em: < http://www.monica.com.br/index.htm >. Acesso em: 25 set. 2019.

SIMIONATTO, I. Gramsci: sua teoria, influência no Brasil, incidência no Serviço Social. São Paulo: Cortez; Florianópolis: UFSC, 2004. 